\title{
Para uma (re)leitura das Anotações sobre as cores de Wittgenstein
}

\author{
João Carlos Salles*
}

\begin{abstract}
Resumo: As Anotações sobre as cores não têm tido o destaque merecido, pois parecem um conjunto parcialmente amorfo e desconexo, com precária estrutura de conjunto. Isso se deve, em grande medida, ao estado da edição dos textos realizada por G. E. M. Anscombe, que despreza variantes, faz sugestões equivocadas para a datação dos manuscritos, suprime parágrafos (inclusive uma quarta parte), além de ter desfigurado a Parte II, ordenando equivocadamente esses parágrafos. Uma edição bem cuidada é necessária à recuperação de suas chaves interpretativas, permitindo-nos um roteiro claro de leitura. Desse modo, a Parte II logo se apresenta como um projeto de tratamento de proposições gramaticais sobre cores, ao que se segue o extenso e rico material da Parte III, a ser lido em conjunto com a Parte IV. Assim, em conjunto, essas partes preparam a bem elaborada Parte I, que sintetiza os principais problemas anteriores e, de modo claro, mostra as razões mais profundas para o fracasso da análise fenomenológica de Goethe e, por conseguinte, de toda fenomenologia que se pretenda uma ciência definitiva do conceito de cor ou que, em relação a outros temas, pretenda universalizar a "matemática" própria de um emprego específico.
\end{abstract}

Palavras-chave: Wittgenstein, Goethe, modelos cromáticos, fenomenologia, necessidade.

Abstract: The Remarks on Color have not had its deserved prominence, for they seem like a partially amorphous and disconnected set, with a precarious structure as a whole. This is due, to a great extent, to the state of the texts edition carried out by G. E. M. Anscombe. Her edition ignores variants, makes mistaken suggestions to the dating of the manuscripts, suppresses paragraphs (including a fourth part), in addition to

\footnotetext{
* Professor titular do Departamento de Filosofia da UFBA, ora exercendo o cargo de Reitor da Universidade Federal da Bahia. Entre outros livros, publicou A Gramática das Cores em Wittgenstein (2002), O Cético o o Enxadrista: Significaşão e Experiência em Wittgenstein (2012) e A Cláusula Zero do Conbecimento: Estudos sobre Wittgenstein e Ernest Sosa (2017). Também restabeleceu e traduziu o texto das Anotações sobre as Cores, de Wittgenstein (Editora da Unicamp, 2009). Preside desde 2013 a Sociedade Interamericana de Filosofia (SIF). E-mail: jcsalles@gmail.com
} 
disfiguring Part II, sorting out those paragraphs erroneously. A thoroughly prepared edition is necessary to the recuperation of its interpretative keys, allowing for a clear reading script. Thus, Part II is soon presented as a project for treatment of grammatical propositions about colors, followed by an extensive and rich material on Part III, to be read jointly with Part IV. So, as a whole, those parts set the basis for a well elaborated Part I, which synthesizes the main previous problems and, clearly, shows the deepest reasons for the failure in Goethe's phenomenological analyzes and, therefore, in the whole phenomenology that is intended as a permanent science of the concept of color, or that, in regards to other themes, intends to universalize the "mathematics" specific to a particular usage.

Key-words: Wittgenstein, Goethe, chromatic models, phenomenology, necessity.

(...) über die Begriffe der Farben wird man durch Schauen nicht belehrt.

Ludwig Wittgenstein

1. Retorno às Anotações sobre as cores quase duas décadas após tê-las editado e traduzido, e quase uma década após ter sido publicado o livro com o texto restabelecido na Coleção Multilíngues de Filosofia da Unicamp. ${ }^{1}$ Antes de dar conta desta releitura e subsequente proposta de roteiro de leitura, permito-me fazer dois agradecimentos, referentes ambos à publicação dessa edição/tradução, submetida à apreciação da Editora da Unicamp em 1998.

Primeiro, a José Emílio Maiorino, assistente da direção da Editora, que, por dez anos, não esmoreceu em seu empenho por conseguir os direitos autorais para uma edição que, sendo um apaixonado exercício de ecdótica, feria a edição outrora feita e por todos os meios consagrada de G. E. M. Anscombe. Essa luta demorada sobrevive no registro, à página 208: “Tradução autorizada de Bemerkungen über die Farben. A responsabilidade pela fidelidade da tradução cabe exclusivamente à Editora da Unicamp e não é de responsabilidade da Blackwell Publishing Limited."

1 WITTGENSTEIN, Ludwig, Anotações sobre as cores, Campinas: Editora Unicamp, 2009, 208 páginas, edição em alemão e em português. Apresentação, estabelecimento do texto, tradução e notas por João Carlos Salles. 
Em segundo lugar, merece minha gratidão o Prof. Fausto Caustilho, idealizador e então diretor da Coleção Multilíngues. Nosso querido Herr Fausto, já falecido, tinha posições fortes, mas era sensível a bons argumentos, tendo-nos concedido, após intenso debate, uma extraordinária exceção, sem a qual boa parte de nosso esforço perderia seu sentido, bem como perderia em força a nova edição. O resultado dessa longa e amistosa ponderação está cifrado à página 19: "Nota do diretor desta coleção. Excepcionalmente, a Apresentação deste livro é mais extensa que as demais da Coleção Multilíngues, por se tratar de uma edição inédita de texto de Wittgenstein".

Só posso agradecer muitíssimo a ambos, assim como ao apoio e incentivo de Arley R. Moreno. Afinal, qualquer o juízo sobre ela, creio ser essa edição/tradução (que, por sinal, teve uma reimpressão em 2011) a contribuição mais valiosa de meu trabalho como profissional da filosofia à nossa comunidade wittgensteiniana

Feitos esses registros, jogo-me ao texto, sem pretender a imersão vivida antanho, mas tendo agora, por interesse específico, o solo de proposições gramaticais sobre cores (em especial, o tema da incomensurabilidade entre sistemas de descrição da experiência) e, por propósito adicional, a sugestão de um roteiro de leitura.

2. As Anotações sobre as cores já foram consideradas uma massa de textos amorfa e, portanto, secundárias. Salvo melhor juízo, a edição de Anscombe favorece tal juízo negativo, dificultando bastante que sejam vistas sob uma luz adequada, qual seja, a de um projeto de investigação de proposições gramaticais sobre cores (dessas que podem ser extraídas da leitura normativa de qualquer modelo cromático), projeto formulado concomitantemente ao de investigação das certezas triviais constitutivas do solo da experiência e, por essa razão, imunes à dúvida. Ambos os projetos estão presentes, lado a lado, no MS 172, redigido em Viena, no final de 1949, sendo desenvolvida primeiro a investigação sobre cores, e isso, como pretendemos mostrar, em elevado grau de sofisticação. Com as Anotações sobre as cores, temos um projeto de análise de legítimas proposições fenomenológicas, irredutíveis a laços causais, análise acompanhada contudo da recusa, digamos, de uma fenomenologia, uma que se pretenda universal e científica. 
Um roteiro adequado para a apreciação desse projeto deve, em primeiro lugar, ter em conta seu novo contexto teórico. Wittgenstein não retorna ao problema da exclusão de cores, ou seja, não está mais em questão a incompatibilidade ampla que uma cor qualquer teria com qualquer outra, de modo que, por exemplo, se uma mancha visível for azul não poderá i ser verde, ou mesmo ter uma tonalidade distinta de azul. A dificuldade lógica e ampla com a cor, nesse específico sentido, afetaria qualquer objeto físico, razão pela qual, no célebre aforismo 6.3751 do Tractatus, Wittgenstein pode comparar tal incompatibilidade, excluída pela estrutura lógica das cores e relativa a dimensões qualitativas e contínuas, com exemplos oriundos da física, como se os quisesse subordinar então a realidades discretas:

Pensemos na maneira como essa contradição se apresenta na física: mais ou menos assim: uma partícula não pode ter, ao mesmo tempo, duas velocidades; isso quer dizer que não pode estar, ao mesmo tempo, em dois lugares; isso quer dizer que partículas que estejam em lugares diferentes a um só tempo não podem ser idênticas. ${ }^{2}$

Nesse novo contexto, já tendo renunciado há duas décadas ao projeto de uma linguagem fenomenológica, pelo qual cobraria exatidão à representação plástica do percebido, as relações entre cores são agora aquelas normativas, que estabelecem, por exemplo, relações de incompatibilidade restrita. Portanto, não de uma cor com qualquer outra, mas sim de uma cor específica, digamos, o verde, que não pode, no interior de nossa gramática de cores, ser usada especificamente com o vermelho para descrever qualquer experiência perceptiva, de sorte que nos sentiríamos simplesmente desnorteados se saíssemos à procura de um objeto que fosse verde avermelhado.

A mudança de tema, motivada agora por uma reação direta à análise fenomenológica proposta por Goethe, procura dar conta de incompatibilidades internas a específicos modelos cromáticos, que se afiguram como descrições perspícuas de relações gramaticais permitidas entre nossos conceitos de cor. Com isso, temos um novo contexto teórico e, ademais, um novo alvo, a saber, a dieta unilateral de Goethe, que pretende fixar a essência das cores, oferecer-lhes a definitiva cifra fenomenológica, uma que, enfim,

${ }^{2}$ Wittgenstein, Ludwig, Tractatus Logico-Philosophicus, São Paulo, Edusp, 2001, 6.3751. 
poderia instruir e seria confirmada pela autoridade suprema dos fenômenos dados ao olhar -no caso, não os físicos, mas sim os pintores.

Além desse novo contexto iluminar diferentemente o conjunto das Anotações, outro aspecto deve ser levado em conta, constituindo-se mesmo em um roteiro de leitura. Aqui, uma boa orientação cronológica e uma reordenação de parágrafos outrora mal editados podem constituir um bom guia para um texto que, longe de ser informe, é um projeto bem desenhado de investigação, que, de resto, foi cumprido muito a contento, abrindo caminho para a subsequente investigação sobre a certeza.

A leitura das Anotações sobre as cores, com o perdão do aparente pleonasmo, deve começar então por seu começo. Ora, a identificação desse começo foi dificultada por um grave erro de edição de Anscombe, ao qual se somaram erros outros, inclusive de datação dos manuscritos. ${ }^{3}$ Importa sim sugerir uma leitura pela chave fornecida por Wittgenstein, à guisa de adequada estratégia de dissolução de imagens filosóficas, em outras palavras, de terapia conceitual. Deve começar, pois, a leitura pelo primeiro parágrafo da parte II (MS 172) das Anotações, o primeiro parágrafo do primeiro conjunto de anotações desse novo contexto de tratamento dos problemas relativos a incompatibilidades restritas entre cores, que não é o editado por Anscombe, mas sim: "Na filosofia é preciso sempre perguntar: 'Como se pode enxergar este problema de modo a que se torne solúvel?"”4

Esse é o primeiro parágrafo do primeiro conjunto de anotações, pois escrito ao final de 1949. Sugerimos, pois, como um roteiro de leitura, começar com ele, tendo a medida da investigação desenvolvida no subsequente canteiro de obras que são as anotações da Parte III (MS 173), feita a partir de 24 de março de 1950. Após a Parte II, portanto, sugerimos a procura da realização

${ }^{3}$ Não retornarei aos argumentos e demonstrações que atestam o erro de Anscombe.
Remeto o leitor aos textos: "Considerações sobre a edição das Bemerkungen über die
Farben", in Manuscrito, v. 7, n. 2, 1997; “On Remarks on Colour”, in Princípios, v. 13,
2006 (este disponível no site www.efg.ufba.br, no qual estão disponibilizados vários
textos produzidos pelo Grupo de Estudo e Pesquisa Empirismo, Fenomenologia e
Gramática); "As Anotasões sobre as cores de Wittgenstein", apresentação ao texto editado
na Coleção Multilíngues.
${ }^{4}$ Wittgenstein, Ludwig, Anotações sobre as cores, II, $\ 1$ [11, na numeração de Anscombe]. 
desse projeto no campo aberto de reflexões da Parte III, em conjunto com a Parte IV ou lendo esta parte em seguida, pois a Parte IV (MS 169, folhas 77 80, que não consta da edição de Anscombe), sendo posterior ou concomitante à Parte III, coloca-se na mesma condição de uma preparação para a revisão e seleção de parágrafos feita na Parte I (MS 176, folhas 1 a 22) -a parte mais bem acabada e refinada, na qual se assenta claramente ser paradoxal a pretensão da análise fenomenológica de Goethe, que, por assim dizer, padece da unilateralidade de qualquer fenomenologia, obrigada portanto a reduzir os possíveis jogos de linguagem com cores a um único jogo, no caso, ao que ocorre na paleta, antes das próprias ocorrências cromáticas.

3. Como tornar solúveis os enigmas cromáticos, pelos quais as cores, espaço mesmo da contingência, tecem relações de necessidade, de modo que, misteriosamente, vemos travado como sistema e norma o que, sem qualquer restrição normativa, pareceria resultado exclusivo do acaso de misturas de luzes ou pigmentos?

O projeto de investigação esboçado na Parte II das Anotações procura afastar a confusão conceitual com a qual nos haveríamos se nos colocássemos, "como um boi diante da porta recém-pintada do estábulo", diante de fenômenos e conceitos, sem um modo de produzir alguma ordem nos conceitos. A interrogação filosófica é aquela que pergunta pelo modo de dissolução do problema, é a que procura acompanhar os movimentos por que foram tecidos nós conceituais para assim desatá-los. Não procura a resposta rápida de quem substitui a interrogação conceitual por uma procura de causas. Esse é o caminho geral, o método próprio da filosofia, que, assim, tem seu lugar, "se considero as cores, por exemplo". 5

O caminho, sugere então Wittgenstein, é o de interrogar-se como as cores são representadas, quais as instruções que seguiria um pintor para representá-las. Conceitos se entremeiam a procedimentos. A chave que torna solúvel o problema de pôr uma ordem nos conceitos de cor não é uma pergunta

\footnotetext{
${ }^{5}$ Wittgenstein, Anotações sobre as cores, II, \ 2 [12]. Os parágrafos 1 e 2, recolocados na ordem correta, cumprem a função de introduzir o tema e o método. Não fossem eles os iniciais, o "por exemplo" (“z. B.”) situar-se-ia aí como o "etc.” na classificação dos animais da enciclopédia chinesa de Borges.
} 
sobre a visão, mas por uma técnica de representação, por instruções que podem ser seguidas. ${ }^{6}$

O mistério do branco transparente (um dos exemplos que se repetem em todas as partes das Anotações e que, por isso mesmo, também se repete em nossas considerações) já começa a ser colocado sob nova perspectiva. Não se trata apenas de podermos ou não pensá-lo. Simplesmente, como veremos com mais detalhe, temos técnicas claras de representação de vidros transparentes vermelhos ou azuis, mas não de um branco transparente, por mais que, em abstrato, julguemos haver situações em que encontraríamos um tal objeto. A pergunta pela técnica nos ajuda, pois, a ver diferenças e nos permite ensinar a ver diferenças. E, logo, a ver como essas diferenças se cristalizam no uso, na lógica do uso de nossa linguagem: "Sim, não se fala em absoluto de uma 'luz esbranquiçada!'”7

Essa estratégia orienta uma procura de analogias e de exemplos, fartamente utilizada na Parte III, mas já permite reconhecer a natureza conceitual da análise fenomenológica, ou seja, sua autonomia em relação à física e, de forma mais ampla, à própria experiência, mas também, como veremos, sua limitação essencialista, pois não daria conta de situações de ficção, sendo ela prisioneira de uma dieta unilateral de exemplos. ${ }^{8}$ As considerações de Goethe sobre a participação do branco em misturas não inaugurariam uma dimensão fenomenológica independente, disposta entre a lógica e a ciência. Suas proposições não são proposições da física, mas encontram-se sim (cabe repetir aqui e em outros lugares) comprometidas pela generalização de uma única experiência com a cor, aquela que, dirá Wittgenstein depois, se determina na paleta em que se dispõem os pigmentos.

Ora, uma proposição causal seria o fundamento de uma distinção gramatical? Não! Apenas a gramática pode contrapor-se à gramática. Assim, nessa Parte II, como a solicitar uma investigação, Wittgenstein espalha termos

\footnotetext{
${ }^{6}$ Wittgenstein, Anotações sobre as cores, II, $\int 1-3$ [11-13].

7 Wittgenstein, Anotações sobre as cores, II, \ 4 [14].

${ }^{8}$ Wittgenstein, Anotações sobre as cores, II, S 6-7 [16-17]. Não daria conta de casos por que são pensadas modalidades, em registro mais amplo, no qual o efetivo deve contrapor-se ao possível e ao necessário: "E se então em algum lugar fosse assim", devemos poder indagar.
} 
fenomenológicos (turvo, transparente, luz, colorido), cuja "natureza" cabe esclarecer. Isto é, cabe mostrar que, em um sentido decisivo, são conceituais e não apenas empíricos, já se antecipando a consideração forte de que uma eventual incomensurabilidade se dá no horizonte da confrontação entre gramáticas e formas de vida, para além da empiria:

"A mistura do branco apaga a diferença entre claro e escuro, entre luz e sombras": determina isso com mais precisão os conceitos? Creio que sim. Caso alguém não ache isso, não tem uma experiência contrária à nossa; mas nós não o entenderíamos. ${ }^{9}$

4. No final de março de 1950, Wittgenstein retorna a uma Londres que, vindo de Viena, lhe parece melancólica, e logo começa a escrever sobre cores. A primeira anotação confirma e restringe uma proposição (digamos, gramatical) da fenomenologia de Goethe, vindo a ser esse um tema principal da Parte I das Anotações, pela qual prossegue e se realiza aquele projeto da Parte III: "O perfeito turvo é o branco, o primeiro e mais neutro (gleichgültig) e mais claro preenchimento não-transparente do espaço". ${ }^{10}$

Wittgenstein toma, então, o exemplo da tricolor, a bandeira da França. Nela, não há como o branco não ser a cor mais clara. ${ }^{11}$ Aqui, há uma espécie de matemática da cor, estando dispostos os tecidos monocromáticos lado a lado, assim como estariam as cores na paleta, antes de qualquer mistura e, mais ainda, antes de sua ocorrência em um quadro. Estruturam assim as Anotações essa consideração positiva e negativa da Doutrina das Cores. Por um lado, afirma o mérito de Goethe em reconhecer a força de necessidade de proposições como essa, sendo, por outro lado, a limitação geral de seu projeto (e o de qualquer análise fenomenológica essencialista) a universalização desse jogo com cores (com objetos do mundo e com as palavras) para todos os jogos de linguagem.

O tema preciso é o estatuto de proposições que têm a força de necessidade e, não obstante, são como que descobertas, como se fossem parte

\footnotetext{
${ }^{9}$ Wittgenstein, Anotações sobre as cores, II, \ 19-20 [9-10].

${ }^{10}$ Goethe, J. W., Zur Farbenlehre, in Goethes Werke, vol. XIII, Hamburg, Christian Wegner Verlag, 1955, \147.

11 Wittgenstein, Anotações sobre as cores, III, \ 1-3.
} 
da história natural das cores, como se, enfim, por aparente absurdo, houvesse nesses casos uma espécie de necessidade a posteriori, e nossas proposições sobre cores estivessem sendo usadas na fronteira entre a lógica e a empiria. Precisaríamos, afinal, primeiro ver para poder dizer que o vermelho saturado é mais claro que o azul. "E, entretanto, se eu o visse, então eu o saberia de uma vez por todas, como o resultado de um cálculo."12

Uma história natural das cores, sem que descartemos o acaso das misturas e da percepção, não seria temporal como a história natural das plantas. Logo, não é meramente empiria. Entretanto, o que pode separar uma proposição sobre cores tornando-a norma de representação, o que pode distinguir uma tal proposição de uma mera descoberta passível de verdade ou falsidade, é seu emprego. E essa é a questão da investigação dos conceitos de cor e das proposições de uma "matemática da cor":

(...) nós não a empregamos como uma proposição de história natural, -e a questão é então: com que parece o outro e atemporal emprego?

Pois apenas assim a proposição de 'matemática da cor' deixa-se distinguir daquela de história natural.

Ou ainda: a questão é: Podemos aqui distinguir (claramente) dois empregos? ${ }^{13}$

Afinal, um emprego tem consequências. Não podemos, fora de qualquer circunstância, estabelecer que um matiz seja mais claro que outro e depois encontrar que não seja assim. A consequência dentro desse jogo seria simples: "então você nomeou os matizes falsamente. (Isto é lógica.)" Entretanto, é exatamente isso que parece ocorrer quando comparamos as cores em efetivas ocorrências cromáticas, e as proposições deslizam, nas duas direções, entre a lógica e a empiria -mistério que se dissolve com relativa facilidade, caso vejamos os modos por que, em cada jogo, se fixam os conceitos, servindo-se de gestos e materiais mundanos. Aqui, trata-se do modo singular por que, em empregos específicos, fixamos os conceitos das cores saturadas, bem como dos materiais que, para tanto, retiramos do mundo e transformamos em paradigmas -ou seja, amostras de cor, pigmentos na paleta das cores, etc.

\footnotetext{
12 Wittgenstein, Anotações sobre as cores, III, \ 4.

${ }^{13}$ Wittgenstein, Anotações sobre as cores, III, \ 9-11.
} 
A oscilação na natureza das proposições, ora legítimas ora normativas, com o deslocar do leito por onde pode correr o fluxo da experiência, é um dos legados das Anotações a ser explorado na investigação seguinte sobre a certeza. Firma-se com clareza essa dependência do uso e a fixação por meio de jogos de linguagem como meios para tornar solúveis os enigmas que envolvem os conceitos de cor -em especial, a aparente suspensão do cálculo em certas circunstâncias.

A gramática desenha a margem de liberdade que podemos aceitar no uso de nossos conceitos. Em sendo assim, um modelo gramatical (no seu aspecto normativo e não na possibilidade de localização de um pigmento em um sistema ou na instrução que possibilita para a percepção da harmonia entre cores) é assim uma descrição panorâmica do uso legítimo de nossos conceitos de cor, ou seja, do emprego de palavras para descrever nossa experiência visual de cores. A Parte III é, então, um canteiro de investigação das possibilidades e limites de modelos cromáticos aparentados em traços essenciais comuns: o octaedro e a esfera de Runge, pois nestes não há lugar para um verde avermelhado ou um amarelo azulado (caso tenhamos em conta um problema que se coloca no "equador" do modelo), nem para um cinza luminoso ou um branco transparente (caso tenhamos em conta seu eixo). Também se consolidam nesses sistemas, tendo, à primeira vista, um sabor de truísmo, "verdades" relativas à essência da cor enquanto percepção, como a de que o branco é a cor mais clara.

5. Como nossa intenção é oferecer um roteiro de leitura e não recobrir o mapa inteiro das Anotaçoes sobre as cores, destacamos dois temas centrais da Parte III, que têm importância direta para a Parte I, que é, digamos, o relatório final da pesquisa. Trata-se do problema do verde avermelhado e o do branco transparente, por meio dos quais cifra-se com clareza um importante deslocamento de modalidades na obra de Wittgenstein.

Estamos sendo severos, restringindo-nos a esses dois temas. Afinal, muitos outros se sucedem. Alguns, aliás, antigos, pois questões gramaticais relativas à incompatibilidade restrita já haviam aparecido em outras ocasiões, como nos relata Moore, por exemplo, acerca das conferências de 1930, em que Wittgenstein mostrou sua predileção por modelos cromáticos que têm um quadrado e não um círculo em seu "equador". O quadrado mostraria melhor a 
posição gramatical das cores, uma vez que explicita uma assimetria essencial nos conceitos de cor e destaca a existência de pontos excelsos, ou seja, cores que servem à descrição, mas não podem ser descritas, distinguindo-se assim cores primárias de secundárias não por simples efeito de misturas. Afinal, podemos entender aproximadamente o que alguém quer dizer-nos com um amarelo avermelhado para descrever o laranja, mas teríamos dificuldade de entender o vermelho como um violeta alaranjado. Naquele momento, por sinal, já se fixara bem a distinção entre cor e pigmento. Com efeito, o verde é produzido facilmente pela mistura de azul e amarelo, mas, sendo ele um ponto excelso, não o descreveríamos como um amarelo azulado.

São questões ademais presentes na Parte III: a natureza conceitual da noção de cor saturada, ${ }^{14}$ as cores intermediárias por oposição às primárias (como na questão acima, agora resolvida em jogos de linguagem), ${ }^{15}$ a cegueira para cores, ${ }^{16}$ empregos restritivos ou não de termos para cores,,${ }^{17}$ o parentesco e a oposição entre cores como questão de lógica, ${ }^{18}$ tapeçarias, quadros e outras representações, ${ }^{19}$ o conceito de cor pura, ${ }^{20}$ Goethe e mais Goethe, ${ }^{21}$ a pintura e a paleta, ${ }^{22}$ Runge, ${ }^{23}$ o ver e o ver como, ${ }^{24}$ aplicações de palavras com cores traduzidas em jogos de linguagem, ${ }^{25} \mathrm{o}$ cinza luminoso, ${ }^{26}$ etc., etc. A riqueza de temas e aspectos é imensa, nem todos eles resgatados, por redundantes ou concordantes, na revisão enxuta da Parte I.

\footnotetext{
${ }^{14}$ Cf. Wittgenstein, Anotaçoes sobre as cores, III, \13-18.

${ }^{15}$ Cf. Wittgenstein, Anotações sobre as cores, III, \ 27-30, passim.

${ }^{16}$ Cf. Wittgenstein, Anotacões sobre as cores, III, \31-32, e passim. Em especial, \ 278 e seguintes.

${ }^{17}$ Cf. Wittgenstein, Anotações sobre as cores, III, \ 35, passim.

18 Cf. Wittgenstein, Anotaçoes sobre as cores, III, \46, e passim.

${ }^{19}$ Cf. Wittgenstein, Anotações sobre as cores, III, \ 37, e passim.

${ }^{20} \mathrm{Cf}$. Wittgenstein, Anotações sobre as cores, III, \58, e passim.

${ }^{21}$ Cf. Wittgenstein, Anotações sobre as cores, III, \57, e passim.

${ }^{22}$ Cf. Wittgenstein, Anotações sobre as cores, III, \68, e passim. Em especial, o \132, que terá posição de destaque na reordenação da Parte I.

${ }^{23}$ Cf. Wittgenstein, Anotaçôes sobre as cores, III, $\int 94$, e passim.

${ }^{24}$ Cf. Wittgenstein, Anotações sobre as cores, III, \270, seguintes e, ademais, passim.

${ }^{25}$ Cf. Wittgenstein, Anotações sobre as cores, III, passim, sendo exemplar o \ 131.

${ }^{26} \mathrm{Cf}$. Wittgenstein, Anotações sobre as cores, III, \ 215 e seguintes.
} 
Voltemo-nos, porém, a dois temas centrais e, em seguida, à razão de sua centralidade. Esses dois problemas são recuperados por Wittgenstein em uma extensa e rara citação, que retoma um texto de Philip Otto Runge dirigido a Goethe:

Runge a Goethe: "Caso alguém deseje imaginar um laranja azulado, um verde avermelhado, ou um violeta amarelado, sentir-se-á como em um vento norte vindo do sudoeste."

Do mesmo modo: "Branco e preto são ambos não-transparentes, corpóreos... Água branca que seja pura é tão inimaginável quanto leite cristalino. Se o preto apenas escurecesse, poderia bem ser cristalino; como, porém, ele suja, então não o pode ser." 27

Propícia a descrição de Runge, sendo sugestiva do que seria perder o norte e o rumo, não ter orientação no interior de uma gramática. Primeiro, não há verde avermelhado, ou melhor, não podemos acolher essa expressão em nossa gramática, mesmo que possamos "imaginar", fora de nossa gramática, uma aplicação conjunta para essas palavras. O sistema se impõe. Podemos traduzir em jogos de linguagem a demanda e solicitar que nos tragam verdes de diversa combinação, assim como podemos pedir que nos tragam exemplos de polígonos. Não saberíamos seguir a regra. Após trazermos tipos de verdes mais claros e mais escuros, amarelados e azulados, não saberíamos como atender a solicitação de um verde avermelhado, assim como após trazermos retângulos, triângulos e outros polígonos, não saberíamos como trazer um biângulo regular.

Pergunte assim: Você sabe o que significa "avermelhado"? e como você mostra sabê-lo?

Jogos de linguagem: "Mostre um amarelo (branco, azul, marrom) avermelhado!" - "Mostre um ainda mais avermelhado!" - "Um menos avermelhado!" etc. Caso domine então este jogo, será exigido de você "Mostre um verde algo avermelhado!" Suponha então dois casos: O primeiro: Você aponta por conseguinte para uma cor (e sempre para a mesma), por exemplo, para um verde-oliva - o outro: Você diz, "Eu não sei o que isto significa", ou "Isto não existe".

${ }^{27}$ Wittgenstein, Anotações sobre as cores, III, $₫ 94$. 
Poder-se-ia estar inclinado a dizer que têm, um e outro, diferentes conceitos de cor; ou um outro conceito de '....ado'. ${ }^{28}$

A solução parece passível de redução à preferência anterior de Wittgenstein pelo quadrado em vez do círculo, com a ideia de que temos pontos excelsos e, por conseguinte, entre o verde e o vermelho temos, de cada lado, duas estações intermediárias, o amarelo e o azul. A diferença, porém, é decisiva. Agora, a questão se resolve por meio de jogos de linguagens, por aplicações de palavras, pela capacidade ou não de dominar e seguir uma regra, com o agravante essencial de não ser inconcebível pensar ou produzir um possível sentido para a aplicação conjunta dessas palavras incompatíveis, sem que precisemos, todavia, acolhê-las em conjunto em nossa gramática das cores.

Essa dissolução do problema pela sua remissão a jogos de linguagem, que podem ser distintos e constitutivos em separado de diferentes conceitos de cor, permite-nos aproximar a solução do problema do verde avermelhado daquele ainda mais intrincado do branco transparente, tornados claros ambos (e toda a dificuldade formulada por Runge) por meio deste novo arsenal filosófico: “A pergunta é: É a construção 'um corpo branco transparente' como a construção 'biângulo regular'?’'29

Nesse caso, porém, a solução prepara uma crítica demolidora dos impasses conceituais da Doutrina das Cores de Goethe. Como Goethe o faria, Wittgenstein parece chamar a depor o pintor, mas este não passa a depor como alguém acaso dotado de um aparato visual mais privilegiado. É como se o pintor nos ensinasse sobre cores não pelo olhar, mas com as mãos, ou seja, pelas instruções de pintura com que representaria, em um quadro, um vidro branco transparente. O pintor consegue dar respostas consistentes para a representação de cada objeto colorido que desejasse apresentar como estando por detrás de um vidro amarelo, vermelho, azul ou verde. Entretanto, suas instruções entram em colapso com o branco transparente. As contradições entre os conceitos se avivam:

${ }^{28}$ Wittgenstein, Anotações sobre as cores, III, \ 30. Retiramos as variantes nesta citação.

${ }^{29}$ Wittgenstein, Anotações sobre as cores, III, \ 138. 
O que deve pintar o pintor que deseja produzir o efeito de um vidro branco transparente?

Deve esbranquiçar vermelho e verde (etc.)?

Não consiste a diferença simplesmente em que cada vidro colorido deve colorir o branco, enquanto o meu ou o deixa inalterado, ou simplesmente precisa escurecê-lo?

Através de um vidro colorido, o branco aparece na cor do vidro. Isso é uma regra para o aparecer da transparência. Assim, o branco aparece branco, através do vidro branco, portanto, como através de um não-colorido. ${ }^{30}$

Tudo isso seria passível de uma demonstração bem mais complexa, e nos consumiu mesmo boa parte de uma tese inteira. ${ }^{31}$ Entretanto, destacamos agora alguns aspectos fundamentais desses dois exemplos e a eles comuns, por meio dos quais fica claro o tipo de decisão sobre cores que, quando envolve necessidade, depende mais do modo por que se cristalizam em empregos específicos da linguagem do que pelo que aprenderíamos pelos olhos. Em particular, como razão para a centralidade desses dois exemplos, cabe destacar neles a clara desvinculação entre impossibilidade gramatical e incapacidade para produção de exemplos, não sendo possível definir a necessidade como sendo o verdadeiro em todos os mundos possíveis, se o próprio conjunto dos mundos possíveis ultrapassa, por algum olhar universal, nossa circunscrição gramatical.

Por que destacamos aqui essas questões? Qual a novidade? O saldo fundamental é haver agora um deslocamento claro nas modalidades. O necessário deixa de coincidir com o universal, o que nos parece ser a medida fundamental da mudança entre a obra madura de Wittgenstein e o Tractatus. Podemos bem imaginar um momento em que a aplicação conjunta de verde e vermelho fosse pertinente, por exemplo, na transição de cores que algumas folhas poderiam apresentar, assim como poderíamos imaginar uma substância que, como em uma tela de cinema exibindo um filme em preto e branco, funcionaria como um vidro branco transparente, com as cenas ocorrendo em

\footnotetext{
${ }^{30}$ Wittgenstein, Anotações sobre as cores, III, \198-200. Retiramos na citação variantes do texto.

${ }^{31}$ Cf. Salles, J. C., A gramática das cores em Wittgenstein, Campinas, CLE-Unicamp, 2002, em especial, por óbvio, os capítulos "O verde avermelhado" e "O branco transparente". A tese também está disponível na página www.efg.ufba.br, mencionada anteriormente.
} 
verdade atrás do vidro. Esses dois casos não são, stricto sensu, impossíveis, mas mesmo assim não nos veríamos obrigados a acolhê-los em nossa gramática, como se incorporados por um capítulo adicional de uma história natural da cor.

6. Sigamos nosso roteiro de leitura. A Parte IV, acrescentada apenas na edição brasileira, foi provavelmente redigida no momento em que Wittgenstein se voltava ao tema do branco transparente, devendo essa parte do MS 169 (com quatro de seus oito parágrafos relativos ao vidro branco transparente) ser coetânea à redação do MS 173. Importante é que, com a Parte IV, temos bem uma chave para afastar todo enigma em relação à cor, bem ancorado esse enigma em uma falsa imagem. E, sabemos bem, "A falsa imagem confunde, a imagem correta ajuda". 32

A falsa imagem aqui é a mais trivial. A própria noção de um "puro conceito de cor", um que pensássemos poder extrair de nossos conceitos ordinários. Não cabe simplesmente excluir a possibilidade de um branco transparente, mas apenas de que não teria lugar em nossos jogos, não devendo haver restrição prévia e universal aos jogos possíveis. Ver o impasse das instruções não deve fazer com que a gramática produza monstros físicos, que escapariam a nossos laços necessários, nem que aberrações da natureza se imponham como verdades gramaticais, como se novas descobertas pudessem ampliar-nos algum limite de possibilidades.

Um branco visto através do amarelo não seria branco amarelado, mas sim amarelo. Deve o amarelo, visto através do branco, tornar-se amarelo esbranquiçado ou branco? No primeiro caso, o vidro 'branco' tem o efeito de um incolor; no segundo, de um não-transparente. ${ }^{33}$

Simplesmente, o conceito 'puro' de cor é uma quimera, pois não há conceito de cor capaz de coincidir inteiro com todas as percepções ou que, por alguma tradução, dê conta de todas as variações possíveis. Tampouco há um momento de pura contingência, infenso à linguagem e às aplicações efetivas de palavras para cor. Não há um ver puro, anterior a todo ver, por cuja invocação

\footnotetext{
32 Wittgenstein, Anotações sobre as cores, III, \ 20.

${ }^{33}$ Wittgenstein, Anotações sobre as cores, IV, $\int 4$.
} 
apenas aguardaríamos a cifra a ser colada, em cada jogo, ao que acaso se nos disponha ao olhar. Não há enfim um jogo perene, a atravessar todos os jogos possíveis - um ver de cores que, assim, não seria jogo algum, como uma caixa de madeira, na qual, enfim, além de guardarmos as peças de um jogo de xadrez, guardássemos todos os jogos possíveis.

7. Todas as anotações preparam enfim a chave mais forte (que já antecipamos) da devastadora crítica de Wittgenstein à análise fenomenológica de Goethe. Podemos ir enfim à Parte I, que substancialmente retoma e revisa as questões pensadas na Parte III, mas agora as ordena segundo um aspecto central, a saber, a crítica à proposição "O branco é a cor mais clara", que podemos ver melhor por ela selecionar um alvo central: o desafio à "análise fenomenológica unilateral" de Goethe, com nossa sugestão de que tal expressão comporta um pleonasmo, uma vez que toda e qualquer investigação fenomenológica estaria baseada em uma dieta unilateral de exemplos. Em sendo assim, além de apresentar sinteticamente os resultados da investigação anterior, a Parte I se organiza em torno da denúncia de um paradoxo e de uma conclusão forte.

A denúncia de um paradoxo, pois Goethe escolhera os pintores como sua autoridade última em matéria da cor. Porém, afirma Wittgenstein: "Eu não consigo imaginar que as observações de Goethe sobre o caráter das cores e combinações de cores possam ser úteis ao pintor; e mal servem ao decorador." 34

Sendo um corolário dessa denúncia, como veremos, uma frase misteriosa, que apenas esse contexto de confronto com a específica análise de Goethe nos permite escrutinar-lhe o sentido. Afinal, atingindo em particular o projeto da Doutrina das Cores, Wittgenstein pode refletir sobre todo essencialismo dogmático, do qual ele não deixou de acusar a si próprio, ao perceber no Tractatus uma visão limitada e unilateral de uso da linguagem: "Embora não haja uma fenomenologia, há decerto problemas fenomenológicos". 35

\footnotetext{
34 Wittgenstein, Anotações sobre as cores, I, \ 73.

35 Wittgenstein, Anotações sobre as cores, I, \53.
} 
Recuperemos, porém, em linhas gerais, os núcleos argumentativos da Parte I. Com isso, sabendo que nos repetimos em parte, como a chamar a atenção, em exercício de metalinguagem, para o que estamos fazendo, estamos justificando a motivação inicial e a feliz condição nova do roteiro ora proposto. Em suma, as Anotacõoes sobre as cores ainda não têm tido o destaque merecido, pois se afiguram muitas vezes como um conjunto parcialmente amorfo e desconexo, com observações interessantes aqui e acolá, mas pouca estrutura de conjunto. Parte disso, segundo julgamos, se deve ao estado da edição dos textos realizada por G. E. M. Anscombe, que é a base para a quase totalidade das traduções. Essa edição, porém, despreza variantes, faz sugestões equivocadas para a datação dos manuscritos, suprime parágrafos, inclusive uma quarta parte, além de ter desfigurado a Parte II, ordenando equivocadamente esses parágrafos. Essa a motivação inicial de nossa reflexão.

O contexto novo é claro. Com a edição bem cuidada de que dispomos, publicada aliás há dez anos, um roteiro de leitura pode ser oferecido, e é o que estamos fazendo, sugerindo o começo da leitura pela Parte II, que, ordenada corretamente, logo se apresenta como um projeto de tratamento de proposições gramaticais sobre cores. Segue-se a ela a leitura do grande e rico material da Parte III, na qual são tratados temas os mais diversos, mas dos quais destacamos a confrontação com Goethe e as específicas proposições "Não há um verde avermelhado" e "O branco não pode ser transparente". A Parte IV pode ser lida concomitantemente à Parte III, de modo que todas elas, em conjunto, preparam a bem elaborada Parte I, que revisa e refina todo esse material, sintetizando os grandes problemas anteriores e, de modo claro, mostram as razões mais profundas para o fracasso da análise fenomenológica de Goethe e, por conseguinte, tal como temos insistido, de toda fenomenologia que se pretenda uma ciência definitiva do conceito de cor ou que, acerca de outros temas quaisquer, pretenda universalizar a "matemática" própria de um emprego específico.

A análise da Parte I, que passamos agora a concluir, mostra, enfim, quão bem organizado, bem acabado e denso é esse conjunto de manuscritos, dando conta do modo por que Wittgenstein cumpre o desafio, que ele mesmo enuncia, de uma radical leitura filosófica: "Em cada problema filosófico sério, 
a incerteza desce às raízes. É preciso sempre estar preparado para aprender algo completamente novo." 36

8. Os enigmas se dissolvem quando traduzimos em jogos de linguagem o que antes parecia definir-se pelo simples olhar. Não é por remissão a um ver interior, a um elucubrar íntimo, que podemos decidir se o verde é uma cor primária ou misto de azul e amarelo, por qualquer criança o produzir por mistura. Não é um ver, de resto, intransferível, mas antes a aplicação concordante de palavras que pode decidir se jogamos o mesmo jogo e se, por exemplo, nos deparamos todos com as mesmas estações intermediárias, de sorte que para nós um amarelo não se aproximaria jamais do azul sem antes passar pelo verde. Aqui decidem jogos de linguagem, ${ }^{37}$ por meio dos quais apenas podemos saber se interna e atemporal ou se temporal e externa uma relação, sendo claro que é externa a relação de claridade entre um e outro corpo dados no mundo, mas interna a relação de claridade entre as próprias cores. ${ }^{38}$

Os enigmas podem, portanto, ser traduzidos em jogos de linguagem. Se envolvem instruções, não precisamos mencionar disposições anímicas. Também importa insistir. Trata-se de jogos, de distintos jogos e, logo, de distintos conjuntos de instruções, por amparadas que o sejam em substratos empíricos. Pode ocorrer então uma contradição entre os empregos, sem que devamos nutrir qualquer esperança de tais diferenças poderem ser reconduzidas a um conceito de cor ainda mais puro, um que subsumisse e explicasse todas as possíveis diferenças. Em especial, cumpre destacar a oposição entre as combinações subtrativas de matérias de cor, de pigmentos e tintas, e a ocorrência cromática ela mesma, na qual conceitos outros se conjugam, e isso de forma tão complexa que não podem ser reduzidas suas relações àquelas próprias da matemática da cor de uma paleta ou dos pedaços monocromáticos de tecidos em bandeiras ou colchas de retalhos. ${ }^{39}$

\footnotetext{
36 Wittgenstein, Anotações sobre as cores, I, S 15.

${ }^{37}$ Cf. Wittgenstein, Anotações sobre as cores, I, \ 6.

$38 \mathrm{Cf}$. Wittgenstein, Anotações sobre as cores, I, $\mathbb{\int} 1$.

${ }^{39} \mathrm{Cf}$. Wittgenstein, Anotações sobre as cores, I, \ 2.
} 
A lógica de um jogo não anula a de um outro. ${ }^{40}$ Pode assim haver, de modo mais radical, empregos consistentes de palavras para cores que não têm lugar em nossos jogos. Nesse caso, podem ser consistentes sem que signifiquem sequer uma capacidade física adicional, pois a mudança não estaria na visão, mas sim nos conceitos de cor. A esse respeito, a Parte I apresenta três parágrafos decisivos para uma nova concepção de modalidade, confrontados eles com três proposições gramaticais, as duas antes mencionadas ("Não há um verde avermelhado" e "O branco é não-transparente") e uma terceira ("O cinza não pode ser luminoso").

No $\int 14$, relativo ao 'verde avermelhado' ou a seu equivalente 'azul amarelado', admite ser possível sim haver outro sistema cromático, ou seja, outra aplicação consistente de palavras para algo que consideramos manter ainda suficiente analogia com nossos conceitos de cor. Não obstante, tal sistema não será simplesmente aceito, nem afetará a força de necessidade das relações internas que perfazem nosso próprio sistema:

Mas mesmo se houvesse homens para os quais fosse natural empregar de modo consequente a expressão "verde avermelhado" ou "azul amarelado", e que nisto talvez também exibissem aptidões que nos faltam, ainda assim não seríamos obrigados a reconhecer que vejam cores que nós não vemos. Não há decerto nenhum critério em geral reconhecido para o que seja uma cor, salvo o de ser uma de nossas cores. ${ }^{41}$

Objeção semelhante volta-se ao problema do 'branco transparente', pela qual o necessário é apresentado como distinto do universal, não sendo abalado pela possibilidade de "imaginação" de uma situação anômala:

No cinema podem-se às vezes ver os acontecimentos do filme como se estivessem atrás da tela e esta transparente, como se fora uma lâmina de vidro. $\mathrm{O}$ vidro tomaria das coisas suas cores e deixaria passar apenas $\mathrm{o}$ branco, o cinza e o preto. (Não praticamos física aqui, mas sim consideramos o branco e o preto como cores tanto quanto o verde e o

\footnotetext{
40 "Se eu digo de um papel que ele seja branco puro, e fosse disposta neve junto ao papel e este então parecesse cinza, com razão porém nomeá-lo-ia ainda branco em sua ambiência normal, e não cinza-claro" (Wittgenstein, Anotações sobre as cores, I, \5).

${ }^{41}$ Wittgenstein, Anotações sobre as cores, I, S 14.
} 
vermelho.) - Poder-se-ia portanto pensar que nós imaginamos uma lâmina de vidro passível de ser chamada de branca e transparente. Entretanto, nós não estamos tentados a chamá-la assim: quebra-se portanto em algum lugar a analogia, por exemplo, com um vidro verde transparente? ${ }^{42}$

Repete-se a resistência a que uma questão gramatical tenha uma resposta física, ou a que a ampliação do baú dos possíveis possa ser exterior à determinação gramatical e lhe comprometa a necessidade. Um objeto do mundo não redime nem corrige nossa gramática. Se a analogia se quebra, se temos aí um limite, longe de ser uma danação, isso é sinal de haver aí uma estrutura normativa. Afinal, onde todas as analogias são possíveis e nenhuma se quebra, onde não há interdição combinatória alguma, não há gramática, ou seja, tampouco pode haver a margem de liberdade que depende da natureza normativa do emprego de palavras para cores.

Aqui, importa acrescentar: a contradição a que podemos ser levados, caso pretendamos ir longe demais com a analogia, não é uma que se resolveria pela descoberta de distinções miúdas, resultantes de uma espécie de inteligência analítica. Dessa forma, não basta dizer que, ao fim e ao cabo, estaríamos empregando a palavra 'branco' em dois sentidos, em um dos quais, o normalmente voltado para a aparência de superfícies, ele não pode ser transparente, mas seria possível haver uma outra palavra que desse conta de sua aplicação para objetos transparentes. A terapia gramatical não coincide com a procura de distinções técnicas artificiais. Poderíamos inventar uma palavra, mas estaríamos desconfortáveis, como em uma roupa tomada de empréstimo às pressas, permanecendo pois "a questão acerca de por que não há uma palavra de cor correspondente à palavra 'branco' para algo transparente". ${ }^{43}$

A distinção se dá ou não no próprio emprego e não em alguma reflexão de gabinete. Por isso, a suposta ausência da palavra não resulta de não termos encontrado ainda um objeto a nomear: "Um meio através do qual uma amostra preta e branca (um tabuleiro de xadrez) apareça inalterada não será chamado um meio branco, mesmo se através dele as outras cores perderem em coloridade." 44

\footnotetext{
42 Wittgenstein, Anotações sobre as cores, I, \ 25.

43 Wittgenstein, Anotaçoes sobre as cores, I, $\int 46$.

${ }^{44}$ Wittgenstein, Anotações sobre as cores, I, \47. Grifo nosso.
} 
Assim como esse, outros exemplos poderiam ser inventados e outros objetos talvez encontrados. Não terão lugar em nossa geometria. Encontrássemos tais meios, e eles todavia não teriam lugar em nossos jogos, pois não se trata de acrescentar uma distinção reconhecível em um pantone (referência para especificação de cores), mas sim do modo como se organiza nossa experiência perceptiva com cores; em suma, da lógica de nossos conceitos de cor. E as cores não são pigmentos, não são coisas com propriedades: "A não-transparência não é uma propriedade da cor branca. E tampouco a transparência uma propriedade da cor verde." ${ }^{45}$

As propriedades das cores, diferentemente das propriedades das matérias de cor (tintas, pigmentos, raios luminosos), não emanam da essência de alguma cor supostamente pura, mas são sim as travadas por nossos jogos. E, dessa maneira, o conjunto de proposições sobre a cor (não sobre os pigmentos) não é uma soma de postulações científicas, como imaginava Goethe ao pretender refutar Newton. Mesmo mencionando iluminações, ambiências e experiências diversas, "essas são proposições sobre os conceitos 'branco' e 'cinza”. ${ }^{46}$ Portanto, não se negam com experimentos ou exemplos da história natural da cor.

Enfim, mais um exemplo, confrontado agora à proposição de que um cinza qualquer pode ser iluminado, mas nunca luminoso:47 "Sou informado de que uma certa substância queimaria com uma chama cinza. Sem dúvida, eu não conheço a cor das chamas de todas as substâncias; por que então não deveria ser isso possível? 48

Ora, em todos esses casos (sobre o cinza luminoso, o verde avermelhado ou o branco transparente), não decide a física nem a psicologia da cor, mas sim os jogos de linguagem, instalados que estão em específicas formas de vida, nas quais apenas pode se dar o comércio com palavras para cores. Em todos esses casos, não podemos "imaginar" (noção que devemos esclarecer melhor), mesmo quando supomos que algo possa ser imaginado por algum povo.

\footnotetext{
45 Wittgenstein, Anotações sobre as cores, I, S 45.

46 Wittgenstein, Anotações sobre as cores, I, \ 49.

${ }^{47} \mathrm{Cf}$. Wittgenstein, Anotações sobre as cores, I, \ 36.

48 Wittgenstein, Anotações sobre as cores, I, $\int 41$.
} 
A imaginação não tem aqui medida pneumática nem behaviorista, sendo ambas as análises tradicionais do imaginar simplesmente ruins. Imaginar, então, é capacidade derivada da lógica dos conceitos empregados, com independência inclusive do que vemos. ${ }^{49}$ "Imaginar", portanto, não se reduzindo a um comportamento, não sendo ele o resultado de laços externos, nem estando em uma desmedida dimensão pneumática, mentalista, também se determina no âmbito de uma gramática.

Não há propriamente pensamento se todos os gestos valem, se não há qualquer restrição. Seria algo como haver um pensar ilógico, ideia afastada, se bem que por outras razões, até ao tempo do Tractatus. Dirá, porém, nas Anotações: "Não se pode imaginar isto', quando se trata de lógica, significa: não se sabe o que se deve imaginar aqui." 50 Resolve-se, pois, em regras o imaginar, sem suprimir com isso a experiência da visão. Ou seja, pensar é ter uma regra de construção, enquanto não poder pensar equivale a não ter como nos orientar, é não haver instruções a seguir.

Não podermos pensar, então, um branco transparente, é não termos regras a seguir para a representação da aparência do branco transparente. Por isso, tomados por uma ilusão fenomenológica, poderíamos avançar com a analogia para além de suas possibilidades, como se, amparados na essência da cor, imaginássemos não haver limites, como se $o$ conceito essencial da cor ignorasse a limitação dos jogos por que se constitui cada conceito e pretendesse, além de qualquer gramática, dar conta de todos os casos.

9. Tudo isso se ampara, ilustrando-a bem, na essencial indeterminação no conceito de cor ou de identidade de cor, perante a qual não cabe haver apegos essencialistas. Por isso mesmo, na Parte IV, rejeitando a falsa idealização, a quimera do 'puro' conceito de cor que se quer extrair de nossos conceitos ordinários, Wittgenstein aponta o absurdo que seria pretender tornar universal o modo de falar que exatamente vale bem em um jogo de linguagem, querendo que se aplique "em um outro jogo, no qual esse modo de falar não tem lugar". ${ }^{51}$ Não havendo o tipo único, o modo único de falar, isso não

\footnotetext{
${ }^{49}$ Wittgenstein, Anotações sobre as cores, I, \ 40.

${ }^{50}$ Wittgenstein, Anotações sobre as cores, I, \ 27.

51 Wittgenstein, Anotações sobre as cores, IV, $\int 6$.
} 
significa a ausência de regras, mas sim que, no que têm de apropriado, valem todos os tipos que podem ser imaginados, ou seja, todos aqueles para os quais temos instruções de representação a seguir. ${ }^{52}$

O enigma reside na ilusão da universalidade de um conceito de cor que, todavia, se mostra indeterminado: "As dificuldades que sentimos ao refletir sobre a essência das cores (e com as quais se queria haver Goethe em sua Doutrina das Cores) residem já na indeterminação / do // de nosso // conceito de identidade de cor." 53

Trata-se, pois, em um exercício de gramática filosófica, de realizar a investigação de essências do que, entretanto, não tem essência além da que se pode agarrar em nossos jogos. Sendo indeterminado o conceito, não tem essência, não é o desdobramento de um único ser, ou o que seja, embora teça relações as mais férreas e incontornáveis. A investigação gramatical não se volta à cor, como se fosse unificar ou suprimir a perspectiva mentalista ou a behaviorista, dando conta da aplicação ao fenômeno da cor das estruturas " $\mathrm{Eu}$

${ }_{52}$ Cf. Wittgenstein, Anotações sobre as cores, I, $₫ 7$.

53 Wittgenstein, Anotações sobre as cores, I, $\ 56$. Citamos acima o parágrafo, tal como se encontra na Parte I, com uma variante, sendo indicado o início da variante com uma '/' e a própria variante colocada entre duas ' //'. Esse é, todavia, um parágrafo notável. Certamente, é um dos mais trabalhados por Wittgenstein no conjunto das Anotações, exatamente por ser esta uma ideia central, que identifica a raiz incontornável da constituição de problemas fenomenológicos legítimos e díspares, sem que possam ser subordinadas a uma fenomenologia. Vale assim a pena citar a formulação abundante desse parágrafo, tal como se encontra na Parte III e como a edição conserva integralmente: "[/] As dificuldades que / encontramos ao refletir sobre a essência das cores // se sentem ao refletir sobre a essência das cores // (às quais quis Goethe fazer frente com sua doutrina das cores), / encerram-se já em não termos / apenas um // um // conceito da igualdade cromática, mas sim vários deles, uns aos outros aparentados. // residem já na multiplicidade de aspectos de nosso conceito de igualdade cromática. // // encerram-se já na / multiplicidade // multiformidade // dos conceitos aparentados da igualdade cromática. // // encerram-se já na / multiplicidade // multiformidade // / do // de nosso // conceito de igualdade cromática. //." (Wittgenstein, Anotações sobre as cores, III, \251.) 
sinto X", mentalista, e "Eu observo X", behaviorista, pois as duas são insuficientes, não podendo contudo cada uma suprimir a lógica da outra. ${ }^{54}$

Tampouco podemos pretender a dissolução das dificuldades com os conceitos de cor pelo retorno de projetos como o de uma linguagem fenomenológica, uma linguagem plástica que fosse anterior e sustentasse mesmo uma linguagem na qual estariam discernidos objetos, de sorte que a diferença entre as lógicas dos conceitos de cor fosse enfim remetida a duas dimensões com regras relativamente autônomas, mas diversamente dependentes. Poder-se-ia pensar, então, como em um retorno a projetos nutridos e negados entre 1928 e 1930, em uma linguagem do puro ver, que cifraria então o que, subsequentemente, poderíamos ver como.

Wittgenstein, porém, em momento algum, retorna à ilusão da sensação anterior ao objeto percebido, da linguagem plástica anterior a uma linguagem ao modo da física, como se com elas quiséssemos, ao fim e ao cabo, ter a medida pela qual cotejaríamos o que vemos com a amostra de cor que selecionaríamos ou produziríamos como equivalente ao visto, como se pudéssemos, enfim, indicar o exato matiz do visto: "Eu não digo que uma tal comparação seja desprovida de interesse, mas ela nos mostra que não é em princípio claro como matizes podem ser comparados nem o que significa 'identidade de cor"'. 55

Não é, portanto, claro que se veria o mesmo, jogo a jogo, não sendo atravessada a percepção por um único critério. Por isso, que uma pintura possa ser esmigalhada em pequenos fragmentos coloridos, isso não faz com que nas peças isoladas se mostrem "as cores genuinas dos lugares da imagem". ${ }^{56}$

Wittgenstein recusa assim a ilusão da sensação e da linguagem fenomenológica como anteriores à percepção e à linguagem ordinária, com a qual falamos de cores. Não tem sentido essa redução, assim como não tem sentido supor que vemos primeiro e absolutamente o cinza nos cabelos loiros de uma fotografia em preto e branco, nem vemos composto o objeto por um conjunto primeiro de manchas, reprodutíveis ponto a ponto. "Se a própria

\footnotetext{
54 Wittgenstein, Anotações sobre as cores, I, \ 57.

55 Wittgenstein, Anotações sobre as cores, I, S 59.

${ }^{56}$ Wittgenstein, Anotações sobre as cores, I, \ 60. Grifo de Wittgenstein.
} 
palavra "blond" (loiro) pode soar blond (loira), tanto melhor podem parecer loiros os cabelos fotografados." 57 De modo bem mais direto, nós os chamaríamos de loiros, sendo primária a linguagem ordinária, que nossa fantasia filosófica tende a tornar secundaríssima. As pretensões de restituição visível do visto soam tão absurdas quanto aquela de Goethe, que procurou, com lâminas coloridas, mostrar para as pessoas de visão normal como enfim veria o mundo um cego para o azul. Também nesse caso, recusando seu absurdo, poderíamos perguntar: qual o critério e o sentido dessa comparação?

10. Vamos enfim a nosso ponto, ao modo por que pode tornar-se solúvel o problema. Todo caminho traçado visa a apontar os limites da análise fenomenológica de Goethe, ${ }^{58}$ podendo ser cifrado, como temos dito, um paradoxo em Goethe ter elegido os pintores como autoridade maior do visível, quando a matemática da cor que ele nos apresenta se dá, porém, inteiramente antes da pintura. Sua lógica da cor, compreendida como escurecimento, é a lógica das misturas subtrativas, pelas quais toda mistura afasta a cor do branco, de sorte que, contra Newton, jamais poderia considerar a cor como um compósito qualquer de cores: "Uma coisa era incontestavelmente clara para Goethe: de escurecimentos não pode, por composição, resultar a clareza assim como mais e mais sombras não geram a luz." 59

Concordar com Goethe é imaginar que ele teria reconhecido a exata natureza da cor, mas 'natureza' não pode ser aqui sinônimo de experimento, mas sim de algo que reside em um certo recorte possível e forte do conceito de cor. ${ }^{60} \mathrm{Em}$ sendo assim, todo o conjunto de anotações se ilumina pelo confronto entre os dois parágrafos da Parte I que já citamos, a saber: o $\int 73$, no qual Wittgenstein afirma a situação paradoxal de não poder imaginar que "as observações de Goethe sobre o caráter das cores e combinações de cores possam ser úteis ao pintor; e mal servem ao decorador"; ${ }^{11}$ e o célebre e

\footnotetext{
57 Wittgenstein, Anotações sobre as cores, I, \ 65.

${ }^{58}$ Uma confrontação mais direta é apresentada no texto Salles, J. C., "O Paradoxo de Goethe”, in Cadernos Wittgenstein, 1, São Paulo, USP, 2000, p. 37-55.

${ }^{59} \mathrm{Cf}$. Wittgenstein, Anotações sobre as cores, I, \ 72.

${ }^{60} \mathrm{Cf}$. Wittgenstein, Anotaçôes sobre as cores, I, S 71.

${ }^{61}$ Wittgenstein, Anotações sobre as cores, I, S 73.
} 
misterioso \53: "Embora não haja uma fenomenologia, há decerto problemas fenomenológicos". 62

Simplesmente, a matemática da cor não atravessa todos os jogos. Um uso unívoco de um conceito de cor em um laboratório, por exemplo, assim como a medição exata do tempo em uma experiência científica, não recobre toda experiência possível, nem significa um uso melhor, "mas apenas um refinado em certa direção e no qual algo foi exagerado". ${ }^{63}$ Do mesmo modo, pensar em uma forma determinada de relações entre cores, como as que podem ser inferidas da mistura na paleta, antes da própria pintura, seria uma limitação que os pintores não poderiam respeitar, nem dela se servir.

Por isso mesmo, em lição que ultrapassa a investigação sobre cores e a crítica específica à análise fenomenológica de Goethe, em lição que também se antecipa à investigação sobre a certeza e, em especial, sobre proposições situadas na fronteira entre a lógica e a empiria, Wittgenstein pode afirmar: não há uma fenomenologia. Ou seja, não há uma ciência da visão e do percebido, anterior e posterior a todo visível que acaso possa ser cifrado em nossa linguagem.

Não há, enfim, uma fenomenologia como ciência, uma que teria lugar se os conceitos fossem todos de mesma espécie lógica e a analogia não tivesse limites. Por outro lado, os problemas fenomenológicos, enquanto gramaticais, enquanto determinam o que podemos ou não dizer com sentido, são de todo legítimos. E, assim, legitimada a terapia gramatical, também se reforça a crítica a qualquer essencialismo - um essencialismo que nos retorna como uma falsa e pregnante imagem, com a qual, costuma ser nossa ilusão e tentação filosóficas, desejamos nos antecipar à própria experiência, reduzindo e submetendo os jogos possíveis a uma dieta pobre de exemplos.

${ }^{62}$ Wittgenstein, Anotações sobre as cores, I, \ 53.

${ }^{63}$ Wittgenstein, Anotações sobre as cores, I, \ 3. 